FORMATION Formation emploi

Revue française de sciences sociales

124 | Octobre-Décembre 2013

Pêle-mêle

\title{
Edito : Quand la qualification ne va pas de soi...
}

Jean-Frédéric Vergnies

\section{OpenEdition}

\section{Journals}

Édition électronique

URL : http://journals.openedition.org/formationemploi/4078

DOI : 10.4000/formationemploi.4078

ISSN : 2107-0946

\section{Éditeur}

La Documentation française

\section{Édition imprimée}

Date de publication : 31 décembre 2013

Pagination : 3

ISSN : 0759-6340

\section{Référence électronique}

Jean-Frédéric Vergnies, «Edito : Quand la qualification ne va pas de soi... », Formation emploi [En ligne],

124 | Octobre-Décembre 2013, mis en ligne le 07 janvier 2014, consulté le 30 octobre 2020. URL :

http://journals.openedition.org/formationemploi/4078; DOI : https://doi.org/10.4000/

formationemploi.4078

Ce document a été généré automatiquement le 30 octobre 2020.

(c) Tous droits réservés 


\title{
Edito : Quand la qualification ne va pas de soi...
}

\author{
Jean-Frédéric Vergnies
}

1 Suffit-il de posséder, d'acquérir des compétences ou une qualification pour obtenir ou conserver un emploi? Cette livraison de Formation Emploi montre que cela peut être insuffisant.

2 Tout d'abord parce que tous les jeunes n'aspirent pas nécessairement à cette logique de placement dans l'emploi pendant leurs études. Emmanuelle Maunaye souligne ainsi que les étudiants ne construisent pas nécessairement un projet, fusse-t-il professionnel, et que celui-ci peut aussi s'inscrire dans une logique de réalisation de soi.

3 Obtenir un emploi ne suffit pas, sa qualité est aussi à considérer. Et Delphine Boutin montre, ici dans le cas de la jeunesse malienne, combien la durée entre le premier emploi et un emploi satisfaisant s'avère une longue marche.

4 Le tutorat lors de stages en entreprise serait-il alors l'élément manquant pour mettre le pied à l'étrier de l'entreprise? Catherine Delgoulet, Alexandre Largier et Ghislaine Tirilly révèlent que la mise en place du tutorat, condition essentielle pour les formations en alternance ou les stages, représente encore largement un défi pour les entreprises. En effet, il est difficile à mettre en œuvre, et sa mesure même est problématique.

5 Le recrutement serait ensuite l'étape cruciale qui permettrait d'identifier la qualité de la relation entre qualification-compétences et emploi. Frédéric Gautier attire ici notre attention sur les décalages possibles entre qualification et emploi. Ainsi les jeunes déjà expérimentés dans le domaine, ou très (trop) qualifiés ne sont au final souvent pas retenus au concours de gardien de la paix. La réussite à l'entretien de recrutement se joue bien plus sur des compétences interactionnelles que sur la conformité aux exigences spécifiques du métier de policier.

6 Enfin, après l'embauche, la qualification, les compétences et l'employabilité ne sont pas pour autant durables. Armelle Gorgeu et René Mathieu montrent comment un contexte de suppressions d'emplois détériore les conditions de travail jusqu'à remettre en cause 
la qualification ouvrière et les compétences mêmes des opérateurs dans l'industrie automobile.

7 Tout au long du processus de formation et d'emploi, les liens entre compétences, qualification et emploi ne vont donc pas de soi et, plutôt que les raccourcis du prêt à penser, requièrent des analyses fines, comme le présent numéro en témoigne.

8 Bonne lecture

\section{AUTEUR}

JEAN-FRÉDÉRIC VERGNIES

Rédacteur en chef 